\title{
Serpentinization of ophiolitic rocks, Cache Creek terrane, British Columbia: Implications for carbon sequestration and nickel recovery
}

\author{
K. STEINTHORSDOTTIR ${ }^{1,2^{*}}$, J.A. CUTTS ${ }^{1,2}$, C.C.
} TURVEY $^{1,2}$, G.M. DIPPLE ${ }^{1,2}$, P.M.D. BRADSHAW ${ }^{3}$, D. MILIDRAGOVIC $^{4}$ AND S.M. PEACOCK ${ }^{2}$

${ }^{1}$ Bradshaw Research Initiative for Minerals and Mining, University of British Columbia, BC V6T 1Z4, Canada

(*correspondence: ksteinth@eoas.ubc.ca)

${ }^{2}$ Department of Earth, Ocean and Atmospheric Sciences, University of British Columbia, BC V6T 1Z4, Canada ${ }^{3}$ FPX Nickel Corp., BC V6E 2P4

${ }^{4}$ British Columbia Geological Survey, Ministry of Energy,

Mines and Petroleum Resources, BC V8W 9N3, Canada

The Decar District in central British Columbia is typically interpreted as a dismembered ophiolite and consists of a variety of ultramafic protolith lithologies that are variably altered to serpentinite and listwanite. Alteration minerals include brucite $\left(\mathrm{Mg}(\mathrm{OH})_{2}\right)$, which can be used to sequester atmospheric $\mathrm{CO}_{2}$ and awaruite $\left(\mathrm{Ni}_{3} \mathrm{Fe}\right)$, which is an economically attractive nickel alloy. The abundance, grain size and morphology of brucite and awaruite are variable and the underlying controls on their distribution are unclear. We use petrographic observations and whole-rock and mineral major-element chemistry to characterize the formation, stability, and distribution of brucite and awaruite in order to optimize their utilization within the processing circuit should the deposit be mined.

Brucite occurs as discrete grains, monomineralic aggregates, or thin veins associated with serpentine and/or magnetite and comprises up to 12 vol.\% of a given rock. Awaruite is disseminated, forming both monomineralic and polymineralic grains, rarely intergrown with sulphide. The abundance of brucite and awaruite increases with serpentinization and decreases with carbonate alteration. Our results distinguish three distinct serpentinization stages: 1) early, low-temperature lizardite; 2) high-temperature antigorite ( \pm metamorphic olivine), and 3) rare late-stage chrysotile veining ( \pm antigorite). Brucite growth mainly occurred during stage 1 serpentinization and is most abundant in rocks that originally had high olivine-to-pyroxene ratio. Awaruite growth occurred during both stage 1 and 2 serpentinization and is most abundant from olivine-rich harzburgite ( \pm lherzolite) protoliths. Together, our results indicate that the stability and abundance of brucite and awaruite are controlled by host rock composition, ambient P$\mathrm{T}$ conditions and hydrothermal alteration processes. 